\title{
The Economics of Faith: Using an Apocalyptic Prophecy to Elicit Religious Beliefs in the Field*
}

\author{
Ned Augenblick \\ UC Berkeley
}

\author{
Jesse M. Cunha \\ Naval Postgraduate School \\ Justin M. Rao \\ Microsoft Research
}

\author{
Ernesto Dal Bó \\ UC Berkeley \& NBER
}




\section{Introduction}

The field of the economics of religion has made substantial progress by focusing mainly on the supply side of the market for religion, such as the industrial organization of religious activity. The demand side, linked to the nature of religious beliefs, has received much less attention (Iannaccone (1998)). This paper investigates what is presumably a key driver of the demand side of religion, namely faith (i.e., religious beliefs), through a simple model and a field experiment.

Studying faith poses conceptual and empirical challenges. On the conceptual side, it must be noted that while faith involves beliefs, it has long been associated (even by famous believers such as Pascal (1668) and James (1909)) with a will to believe, suggesting a nonstandard connection between utility and beliefs. ${ }^{1}$ On the empirical side, there are challenges to measuring faith. Authors have noted the potential for individuals to misrepresent their beliefs when asked about religion. ${ }^{2}$ These difficulties suggest the use of incentivized elicitation methods, but religious events are typically unobservable (e.g., God's existence) and therefore participants cannot be rewarded based on accuracy. Despite the long history of religion in human affairs, to our knowledge religious beliefs have never been measured scientifically in an incentivized manner.

In this paper we make three contributions. The first is an approach to bring incentives into the measurement of the level and elasticity of religious beliefs. The key requirement is to locate religious propositions that are (presumably) believed in, and are also falsifiable. Then we can rely on belief elicitation techniques that reward predictions based on their accuracy. The second is the concrete findings of our approach when implemented with a specific religious group, to be described shortly. The third is a formal theory of religious beliefs that explicitly models the experimental intervention and offers a faith-rooted microfoundation for the demand side of religion.

We administered an experiment to implement our elicitation approach, relying on the well publicized prophecy made by Harold Camping, an elderly Christian radio talk show host, who held that May 21st, 2011 would be the "End of the World." On May 21st, the prophecy went, the biblical Rapture would occur: divine judgement would be passed and

\footnotetext{
${ }^{1}$ The dictionary definition of faith separates it from evidence in the statistical or logical sense. According to the Oxford dictionary, faith is "a strong belief in God or in the doctrines of a religion, based on spiritual apprehension rather than proof." See Montgomery (1996) for a discussion of some of the challenges to an economics approach to faith.

${ }^{2}$ Kuran (1995) elaborates on the fact that tendencies to conform may lead to a falsification of preferences and beliefs. See Krosnick and Presser (2009) p. 285 on survey response bias more generally. An alternative to measuring beliefs is to track religious participation, but religious participation may reflect desire for community or material benefits rather than a pure reflection of beliefs.
} 
the "saved" would ascend to Heaven to meet God, while great cataclysms would ravage the Earth. The "non-saved" would suffer "Hell on Earth" for five months, until all of creation would be annihilated on October 21st, 2011. Camping's prediction attracted a world-wide following, driven by tens of millions of advertising dollars and daily discussion on his Family Radio network, one of the largest Christian broadcasting networks in the U.S.

Our experiment elicited beliefs in the End of the World prophecy by having subjects make time-preference decisions in the weeks prior to May 21st, exploiting the espoused belief of Family Radio followers that money would have no value after May 21st. Thus, Family Radio followers should discount money payable after May 21st to reflect their belief that the prophecy would come to pass, in addition to a pure time preference. ${ }^{3}$ In order to approximate a control group we also approached members of the Seventh Day Adventist Church (henceforth, SDA), who are theologically similar to the Family Radio members but, crucially for our study, did not consider May 21 st a special date. ${ }^{4}$ We offered both the Family Radio and the SDA subjects a choice between $\$ 5$ "today" (that is, before May 21st), and a variety of amounts up to $\$ 500$ four weeks in the future (after May 21st), using a BeckerDeGroot-Marschak method (Becker, DeGroot, and Marschak (1964), henceforth, BDM) to capture the exact amount payable after May 21st that would make the subject indifferent with $\$ 5$ today. For the SDA group, we expected a discount rate that exclusively reflects a pure time preference. If beliefs in the prophecy among Family Radio members are a matter of external profession rather than inner conviction, we would expect their choices to resemble those in the SDA group. If their beliefs were sincere, we would expect their revealed discount rates to be higher.

The evidence indicates that the vast majority of Family Radio members held extreme beliefs even in the face of direct financial costs - nearly all Family Radio subjects preferred $\$ 5$ dollars today to any amount up to $\$ 500$ payable after the Rapture. In contrast, the SDA members made choices consistent with time preference parameters estimated in laboratory

\footnotetext{
${ }^{3}$ In fact, there were numerous media reports about believers in the prophecy making material decisions in anticipation of the events of May 21st, such as spending down bank accounts or winding down businesses. Several subjects told us they were making similar decisions; in a survey implemented a posteriori of the experimental interaction $68 \%$ of them reported higher spending as a direct result of their beliefs, with the majority reporting increased spending on donations.

${ }^{4} \mathrm{SDA}$ is a large Christian denomination (16.3 million members worldwide, and the 7th largest denomination in United States) which grew out of the Millerite movement, perhaps the quintessential American apocalyptic group whose members expected Judgement Day to occur in 1843 . Following the failed prediction, the movement split into multiple sects that continue to hold apocalyptic beliefs today, including the SDA Church, who reject date-setting (but who believe that Jesus Christ's return to Earth is "imminent,"), and Jehovah's Witnesses who have maintained date-setting (and continued to make multiple failed predictions). Seventh Day Adventist member statistics are available at www.adventist.org/world-church/ facts-and-figures/index.html.
} 
studies (Frederick, Loewenstein, and O'Donoghue 2002). Taken together, these findings indicate that the Family Radio members held sincere and full beliefs in the prophecy. These beliefs matched the ones they reported in a survey after the experiment. To our knowledge, this initial set of findings provides the first experimental documentation of the role played by sincere faith in the demand for religion. ${ }^{5}$

Our second empirical finding is best discussed in the context of our theory. We motivate our model with the observation that religious beliefs are difficult to justify with standard models of Bayesian updating given the lack of concrete evidence (we abstract from the possibility that beliefs are driven by revelation or grace). Consequently, we follow a literature in economics which has explored how, if beliefs can independently drive utility beyond instrumental value, people might willfully manipulate their own beliefs (see inter alia Akerlof and Dickens (1982), Bénabou and Tirole (2004), Brunnermeier and Parker (2005), Köszegi (2006)). In our model, we replace the psychological drivers in those theories (cognitive dissonance or anticipatory utility) with a simple cost-benefit model mirroring Pascal's wager: agents consider that fully believing in a religious proposition will provide salvation (a positive payoff) if a "religious state" occurs (e.g., God exists), but also recognize that these beliefs entail costly actions (such as prayer) regardless. Given this setup, there is a marginal individual, in terms of initial priors on the religious state, such that all agents with a higher prior deliberately choose to believe fully in the religious state. There are three takeaways from the model. The first is that a rational choice leads a subset of individuals to full and sincere religious beliefs. The second is that such choice can lead individuals with similar priors to separate into extreme believers and skeptics, a polarization that we observe in our experimental data. The third is that a change in the cost of distorted beliefs should affect the prevalence of faith if priors were disperse. We test this third prediction by randomly varying the probability of implementation of the BDM lottery across individuals in our experiment, which directly manipulates the cost of a distorted belief. Our second empirical finding is that we find no evidence that beliefs are cost-sensitive. This second finding creates some ambiguity when interpreting our results. While a price-elasticity of beliefs might be the ultimate evidence of the presence of a demand for beliefs, the lack of elasticity does not disprove the theory, as we discuss in detail after presenting our results.

It may be tempting to dismiss our results as simply reflecting the strange apocalyptic

\footnotetext{
${ }^{5}$ It may be argued of course that sincerity can only be established in relation to the stakes offered in the experiment. Perhaps $\$ 10,000$ would induce different behavior than $\$ 500$. But in other realms where survey bias is also suspected-e.g., politics-the introduction of moderate stakes sharply alters response patterns relative to unincentivized surveys (Bullock and Huber 2013). Thus, we believe it is noteworthy that our elicitation of religious beliefs under conditions of privacy and under reasonably sized stakes replicated the survey-based response patterns.
} 
beliefs of a very small group of mentally-unsound individuals. However, according to a 2010 Pew Research Center survey, 41\% of all Americans believe that Jesus Christ will definitely or probably return to earth by 2050, an event that in Christian Theology is strongly connected to the Rapture. ${ }^{6}$ This is perhaps not surprising as, according to McGinn (1998), "Apocalyptic is the mother of all Christian theology." 7 More broadly, according to (Wagar (1982), p. 36), "Cultures without terminal visions of some kind have in all probability never existed." 8 Rather than concluding these people are disingenuous or lack intelligence, scholars such as Daniel Cohen write that "it would be a mistake, however, to put down the modern catastrophist as a fraud, a fool or a madman. Usually he is honest, intelligent, and quite sane - he is simply devoted to an incorrect idea..." (Cohen (1983), p. 72). These observations suggest that apocalyptic beliefs, rather than reflecting pathology, are deeply lodged in the symbolic and narrative structures with which large parts of the world population have come to organize their sense of justice and history, and therefore that FR members are not terribly distant from many other religious movements.

It may be argued that experiments are unnecessary because we observe many people making material sacrifices for the sake of their religiosity, suggesting that they hold sincere religious beliefs. However, it is important to rule out actions that may be taken for instrumental reasons, such as advancing social, economic, or political goals. ${ }^{9}$ Since it is virtually impossible to rule out instrumental motives when analyzing observational data, it is equally difficult to ascertain true faith. What is unique to our experimental, revealed preference, approach to eliciting religious beliefs is the combination of two key features: the choices made in the experiment were private, and the ensuing consequences were controlled by the experimenters rather than a matter of anecdotal reports by third parties or by the putative believers. However, even our experiment could have been better in the first regard: in order to recruit subjects, we approached them at the very end of a group activity. Although they made private decisions, they might have felt more inclined to make choices consistent with a

\footnotetext{
${ }^{6}$ Both events are associated with the great Tribulation or "end times." According to the Mercer Dictionary of the Bible (p. 736), much of the analysis of the Rapture is based on Greek words Paul uses when referring to Christ's return, such as "coming" (parousía), "appearing" (epiphanía), and "revelation" (apocalipsis).

${ }^{7}$ For example, the story of Noah's Ark is believed by many mainstream Christians, Jews and Muslims, and accepted as a fairly uncontroversial part of the Bible (Genesis 6-9) and Quran (surahs Hud and Al-Muminoon). Many Family Radio billboards used the phrase "Noah Knew," alluding to the idea that to "hear the call of God" provides salvation from disaster.

${ }^{8}$ Interestingly, apocalyptic myths follow a similar pattern across cultures from the Judeo-Christian-Islamic tradition to Persian Zoroastrianism, Hinduism, and Babylonian, Roman, and Greek traditions (Eliade 1954; Wagar 1982). A recurring theme involves the current world ending by a divine intervention that unleashes great catastrophes (floods, fire, earthquakes), and which punishes the sinful and rewards the virtuous.

${ }^{9} \mathrm{An}$ extreme example is that of suicide bombers in the Middle East, which is pertinent since reports indicate that subsequent social approval and transfers to the martyr's family play a role in motivating action (Soibelman (2004), p. 185).
} 
full belief in the prophecy given the environment, perhaps even to make a statement toward the experimenters.

Religion has, of course, attracted vast attention in the social sciences and therefore we will discuss the relatively smaller literature on the demand side of the market for religion. ${ }^{10}$ Ensminger (1997) relies on a transactions costs approach to account for conversion patterns to Islam as a function of the advantages of membership to trading networks, while Levy and Razin (2011) model a context where conversion (real or apparent) confers signaling benefits toward further social interaction. Compatible with that logic, economics fundamentals related to geography and trade feature prominently in recent empirical work on adherence to Islam (Michalopoulos, Naghavi, and Prarolo (2012) and Barro, Hwang, and McCleary (2010)). Closer to our framework, Durkin and Greeley (1991) formalize the Pascalian wager and test the basic predictions on time-series survey data about religion. Unlike ours, their model does not distinguish between actions (i.e., religious participation) and beliefs. ${ }^{11,12}$ An interesting challenge is to empirically disentangle the causal links between economic fundamentals, religious actions, and true beliefs. Such investigation would benefit from a way to measure beliefs more reliably, and the incentivized approach we offer may be of help. Similarly, our paper complements the literature that utilizes survey data, such as that in the World Values Survey, to address the interplay between economics and religiosity (see for instance Barro and McCleary (2006) and Huber (2005)). Finally, our paper complements other work on belief anomalies and manipulation, including theoretical work on belief management through selective information acquisition (see for instance Carrillo and Mariotti (2000), Bénabou and Tirole (2004), and Compte and Postlewaite (2004)) and directed belief choice for intrinsic reasons (see inter alia Brunnermeier and Parker (2005), Köszegi (2006), Bénabou and Tirole (2006), and Dal Bó and Tervio (2013)), as well as laboratory work suggesting non-Bayesian, but directed belief updating given materially self-serving information (Babcock and Loewenstein 1997; Babcock, Loewenstein, Issacharoff, and Camerer 1995), information about personal characteristics (Eil and Rao 2011; Möbius, Niederle, Niehaus, and Rosenblatt 2010; Svenson 1981), or information about performance of other people that the subject cares about (Massey, Simmons, and Armor 2011). ${ }^{13}$

\footnotetext{
${ }^{10}$ The literature on the supply side of the market for religion is well surveyed by Iannaccone (1998). There is also a body of empirical evidence on religion from laboratory experiments; see Hoffman (2012) for a review.

${ }^{11}$ A substantial literature in philosophy has examined both the logic and premises of the Pascalian wager (e.g., Hacking (1972), Hajek (2003)), notably the assumption that the returns to belief are infinite in the state that God exists.

${ }^{12}$ Palacios-Huerta and Santos (2004) study a demand for religion following a more distant approachthey consider an evolutionary competitive argument for religious preferences based on reduced risk aversion against uninsurable states.

${ }^{13}$ Such departures, however, may be due to limitations in the quality of available feedback (Benoit and
} 
The plan for the paper is as follows. The next section offers background on Family Radio. Section 3 outlines the experimental design, Section 4 presents the model, Section 5 presents the experimental results, and Section 6 concludes.

\section{Background}

Family Radio (henceforth FR) is a large Christian talk and music radio broadcasting network; by 2007 it was the 17th largest owner of radio stations in the United States in 2007 and had assets well above the hundred million dollar mark. ${ }^{14}$ For nearly fifty years, FR had broadcast a program on weekdays called "Open Forum," in which the station's co-founder and president, Harold Camping, answers listeners' questions about the Bible.

In early 2005, Camping published a book called Time Has an End: A History of the World 11,013 B.C. to 2011 A.D. (Camping 2005), which contained purported biblical proofs that the Rapture - an event in which a selected few are transported directly to Heavenwould occur on May 21, 2011. On this date, Camping predicted that "great earthquakes will occur" and those not raptured "will exist [for 5 months] in a world of horror and chaos beyond description" until October 21, 2011, when "God will completely destroy this creation and all of the people." An important aspect of Camping's prophecy was that money would have no value after the Rapture, neither for the saved or the damned. This aspect was emphasized repeatedly by Family Radio members in their interactions with us.

Camping's evidence for this prediction largely relies on biblical exegesis and numerology. For example, based upon verses in the Old Testament, Camping believed that the biblical flood involving Noah occurred in 4990 BC of the Roman calendar. Then, taking a statement in Genesis 7:4 ("Seven days from now I will send rain on the earth") as a prediction about the end of the world combined with a statement in Second Peter 3:8 ("A thousand years are like a day"), Camping concluded that the end of the world would occur in 2011, some 7000 years after the flood. Camping used other Bible passages to narrow down his prediction that Judgement Day would occur exactly 722,500 days from the date of Christ's crucifixion (April 1, 33), leading to the May 21, 2011 date. Camping repeatedly stated that there was "no longer any question" about this date, and that "the Biblical evidence is too overwhelming and specific to be wrong." 15 This certainty required resolving contradictions with

Dubra 2011) and a multi-attribute signal space (Santos-Pinto and Sobel 2005).

${ }^{14}$ This information as well as data on expenditures we refer to later is available through IRS 990 forms that all charities are required to publicly disclose.

${ }^{15}$ In 1992, Camping wrote 1994?, a book in which he promoted September 6, 1994 as a potential date for the Rapture; he did not express certainty in this book. However, according to Family Radio literature, "important subsequent biblical information was not yet known, so this book was incomplete." 
scriptural discouragements to engage in apocalyptic date-setting (most notably the statement in Matthew 24:36 that "no man shall know" the exact date) and interpreting many ambiguous passages as metaphorically referring to the end of times. Faced with the same arguments, many other Christians who share the apocalyptic frame of mind, such as SDA members, did not believe in this prophecy.

In addition to the radio program, FR promoted the Judgement Day prediction by spending tens of millions of dollars to place 2000 billboards in over 40 countries and sending multiple R.V. caravans across North America. Camping also held weekly Bible studies at the Alameda Veteran's Memorial Hall, near the station's headquarters in Oakland, CA. By May of 2011, the story of Camping's prediction and his numerous followers was covered by many prominent news outlets, including Time Magazine, New York Times, Washington Post, Los Angeles Times, AP, and Reuters. Many of these reports mentioned that followers were engaging in various behaviors consistent with "end of the world" beliefs, such as spending down bank accounts.

\section{Experimental Design}

We designed an experiment with two goals. One was to elicit beliefs in Harold Camping's Judgement Day prophecy that the "End of the World" would occur on May 21st, 2011. The other was to study the elasticity of those beliefs given changes in the costs of holding them.

To elicit beliefs, we used the well known BDM method (Becker, DeGroot, and Marschak 1964) to elicit the indifference point between a $\$ 5$ present-dated check and some amount of money payable by a post-dated check in four weeks (a date intentionally set post-May 21). To understand the intuition behind the design, recall that Camping's prophecy implies that money would be useless after the Rapture. Therefore, money payable after May 21st would only hold value in the non-religious state in which the Rapture does not occur. A person with a higher belief in the prophecy would require a higher payment after May 21st to maintain indifference with $\$ 5$ payable today. For example, a risk-neutral person with no pure time preference and a $50 \%$ belief in the prophecy would require $\$ 10$ after May 21 to be indifferent with $\$ 5$ payable before May 21st, while a person assigning an $80 \%$ probability to the prophecy being true would instead require $\$ 25$ after May 21.

Before discussing the elicitation of the elasticity of the belief, it is useful to discuss how beliefs might change with their "price." In traditional economics, beliefs do not respond to prices because beliefs are formed mechanically through Bayes rule given a prior and objective signals about the environment. As we discuss formally in the model presented in Section 4, 
our experiment is premised on the idea that people can choose beliefs to balance costs and benefits. A person might choose to believe in the Rapture because this is thought to earn salvation. However, this belief will cause other decisions to be distorted relative to what the prior belief would warrant, which creates a cost in terms of materially driven expected utility. For example, the person may overinvest in efforts to spread the word about May 21st, and make financial decisions in the experiment (as well as outside) as if there were no future. One can imagine that if the cost in terms of suboptimal material decisions becomes more likely, more individuals may decide to forgo the full belief.

In order to experimentally vary the cost of suboptimal beliefs, we randomly assigned participants to two treatment conditions which corresponded to different probabilities that the participant's payment would be tied to his decision in the BDM scheme. Specifically, participants were informed that their decision elicited by the BDM method would be implemented with either a $6 \%$ or a $50 \%$ probability: these probabilities were chosen in order to maximize the range of expected future payments while staying within our experimental budget. This variation defined the two treatment conditions in our experiment. Note that the cost of a distorted belief to a participant varied with the implementation probability, allowing us to test the null hypothesis of a zero price elasticity of beliefs. The experiment was run with two distinct subject groups: FR members and SDA members, which yields a 2x2 group-condition matrix. SDA members hold beliefs similar to those of FR members concerning the existence of the Judgement Day and the Rapture, except that SDA members do not claim to know the precise date.

Importantly, the FR and SDA samples should not be interpreted as treatment versus control subjects since membership is obviously endogenous. The reason we use the SDA sample is to see whether people who hold a belief system that is almost identical to that of the Camping followers, apart from the specific date prediction, tend to have what we think would be normal money-time preferences. If this is the case, it would alleviate concerns that results for the FR members are driven by an inability of subjects to understand the experimental decision, or due to a lack of trust in us as experimenters to deliver on promised future payments.

At this point it is worth making two methodological points. First, in eliciting beliefs, one might prefer to use a method that is robust to risk aversion, such as that by Karni (2009). Unfortunately, using such a method is not possible in our situation as it would require making immediate payments contingent on states that are unobservable (e.g., the Rapture taking place) at the time of payment. However, as we will discuss later, the presence of any reasonable level of risk aversion would not significantly affect our quantitative conclusions. Second, one might consider a potentially more natural experimental design in which 
we vary the experimental payments, rather than the probability of implementation, across the two conditions. This design poses additional problems if individuals are risk averse: payment manipulations can induce changes in declared cutoffs that reflect differences in the curvature of the utility function, rather than changes in underlying beliefs. As we demonstrate in the theory section, we avoid this confounder when manipulating the probability of implementation.

\subsection{Subject recruitment}

FR volunteers were solicited from outside a Bible study led by Harold Camping in a public hall in Alameda, California, on two consecutive Sundays, May 8th and 15th, 2011. SDA volunteers were solicited from the congregation of an SDA church in San Francisco, California, on Saturday, May 14th, 2011 (SDA services are on Saturdays). We estimate that both the Family Radio Bible study meetings and the SDA service were attended by about 100 adults each. $^{16}$

For both groups, we set up a table outside the building where each group met, and upon exit we asked people if they would like to participate in a survey concerning their beliefs. From a design perspective, this recruitment strategy is not ideal if one worries that recent participation in a group activity may affect responses, but there was no other way in which we could approach these subjects. Potential participants were informed that they would receive five dollars cash for participating, that after the initial part of the survey they would get to make decisions that could generate further earnings, then answer a final questionnaire, and that we would donate three dollars to their organization for each completed survey. ${ }^{17}$ About half of the potential subjects we talked with declined to participate after reading the consent form.

It is likely that our recruitment method induced some selection with both groups. First, we likely faced the standard experimental selection problem: the higher a person's valuation of time, the less likely participation is. Second, some members from both groups told us they thought participating seemed too much like gambling, or was a form of work which, according to their beliefs, should not be done on the Sabbath (Sunday for FR members and Saturday for SDA members). Those who refused to participate on these grounds are likely to be stricter Christians than those who did participate, so selection seems to be against hardcore members of the groups.

\footnotetext{
${ }^{16}$ We chose to administer the survey to the San Francisco SDA congregation because they were the nearest SDA Church to the Family Radio Bible study that responded to our request to survey its members after a service.

${ }^{17}$ The donation to the organization helped us garner approval from the organizers of each group.
} 


\subsection{Participant instructions and experimental interaction}

Upon obtaining written consent, participants within each sample were randomly assigned to one of two treatment conditions and given the appropriate decision packet. ${ }^{18}$ They were informed that their answers would not be made public, nor would we collect personally identifiable information. Furthermore, every effort was made to ensure that participants did not talk among themselves and that they made all decisions privately.

Subjects answered two sets of questions and were asked to make a decision between receiving 5 dollars today and different amounts of money in four weeks. The subjects knew the result of this decision would only be implemented with a particular probability $(6 \%$ or $50 \%$ as indicated by their treatment condition). If implementation was selected by the randomization device (flipping coins), the researchers would determine the actual payoff through the BDM lottery described below. Depending on the participant's decision, the subject was either written a present-dated check for 5 dollars or a four-week-post-dated check for the payoff amount. ${ }^{19}$ This payment by check was in addition to the 5 dollars paid in cash for participation. Payments took place in a removed station. No visible differences in the form or procedure of payment took place across subjects depending on their decisions.

We explained the BDM method in a simple fashion. Participants were presented with a picture of 50 circles - representing 50 small balls in bag — with a dollar amount associated with each circle/ball ranging from $\$ 1$ to $\$ 500$. We instructed subjects to circle all of the amounts they would prefer to have in four weeks as opposed to 5 dollars today. As expected, some subjects did not immediately understand the BDM method and were consequently helped by one of the researchers. ${ }^{20}$ We refer to the smallest amount circled as the "cutoff" amount. If they preferred 5 dollars today instead of any of the amounts in four weeks, they were instructed to circle a box stating "I prefer $\$ 5$ today." Subjects were also told that a ball would be drawn, and that if the ball drawn showed an amount lower than the cutoff they would be paid 5 dollars that very day, and that if the ball showed an amount larger or equal than the cutoff then they would be paid the amount shown by the ball in four weeks. Conditional on choosing a 5 dollar cutoff and having the random ball draw implemented, the expected value of playing the game was 79 dollars.

\footnotetext{
${ }^{18}$ The online appendix includes a thorough description of the instructions as well as copies of the decision packets for the $50 \%$ treatment from both groups; the $6 \%$ packet is identical up to the stated probability.

${ }^{19}$ In addition to postdating the check and including the memo "Do not cash this check until [4 weeks hence]," we instructed the bank to temporarily put a stop on the checks for four weeks, and informed participants this had been done.

${ }^{20}$ In these cases, we asked participants to imagine a ball with a particular amount was selected and decide if they would rather "receive that amount in 4 weeks or receive $\$ 5$ today." We roughly estimate that around $20 \%$ of both groups required some assistance with the BDM mechanism. Given the consistency of the cutoff decisions within groups, we believe it is unlikely that the assistance had any effect on decisions.
} 
We surveyed $27 \mathrm{FR}$ members and 29 SDA members. Of the $27 \mathrm{FR}$ members, four were excluded before we analyzed the data. We excluded a mother and daughter pair, as we observed the mother break protocol and approach the daughter to discuss the experiment; we excluded two other subjects because they were merely observers, not Family Radio members. $^{21}$ Thus, our sample for analysis contains 23 FR and 29 SDA subjects.

\section{Theory}

In the previous section, we argued intuitively that our experimental design can elicit the beliefs about a specific religious statement and measure the elasticity of beliefs by manipulating the cost of beliefs. In this section we develop a model of a more general experimental protocol with these characteristics, demonstrate when and how it works, and connect it to our specific experimental design. If the reader is not interested in a theory of faith, and content with the intuitive explanation of our identification approach, this section can be skipped.

In the model, individuals choose their religious beliefs to maximize expected utility in a way resembling the Pascalian wager, trading off a potential spiritual payoff from holding stronger religious beliefs against the potential material costs from suboptimal decisions that follow from those beliefs. ${ }^{22}$ We first model individual behavior in the absence of experimental interaction, and then we explicitly model how the experiment can help characterize religious beliefs. Proofs are relegated to the appendix.

\subsection{Model: Structure and payoffs}

There are three periods, which we discuss in reverse order. In period 3, one of two states of nature is realized: the "religious" or the "non-religious" state. The religious state could be one in which God exists or in which the Rapture occurs on May 21st. If the religious state is realized, the agent receives a spiritual payoff, discussed below. There is a continuum of agents indexed by their prior belief $\pi \in[0,1]$ that the religious state will occur. In period 2 , the agent chooses an action $a \in \mathbb{R}$, which leads to an expected material payoff. For example, the action could be attending church or spreading the word about May 21st, leading to a

\footnotetext{
${ }^{21}$ It became apparent that the mother was a FR member, but did not speak English, while the daughter was not a FR member and was there to accompany her mother. The non-Family Radio members identified themselves to us as such after the experiment.

${ }^{22}$ In a previous version of the paper, we modeled the decision as a (similar) tradeoff between anticipatory utility from religious beliefs and material costs from suboptimal choices. As these two models lead to similar results, we stick with the current model as it is significantly more parsimonious.
} 
certain material cost of time or effort and expected material benefits of answered prayers or avoided divine punishment. We assume that there is a unique action choice that maximizes the expected material payoff, which is strictly increasing in the agent's prior. ${ }^{23}$ In period 1 , in the major deviation from standard economic models, we allow the agent to choose a belief $\hat{\pi} \in[0,1]$ in the religious state. ${ }^{24}$

We assume that there is a potential benefit to the agent from deviating from his prior. Specifically, we model the spiritual payoff $U_{r}$ as an increasing function of the chosen belief $\hat{\pi}$, capturing the common feature of religion that salvation is conditional on belief. ${ }^{25}$ Although many of our results hold given general functions $U_{r}(\hat{\pi})$, we assume a stark functional form: ${ }^{26}$

$$
U_{r}(\hat{\pi})=\left\{\begin{array}{cc}
u_{r}>0 & \text { if } \hat{\pi}=1 \\
0 & \text { otherwise }
\end{array}\right\}
$$

This functional form has the benefit of simplifying many of the results, and is also realistic: a common theme in religious doctrine is that doubtless belief, or "faith" is required for salvation. ${ }^{27}$

There is also a cost to choosing incorrect beliefs. Following the literature on optimal belief choice with anticipatory utility (Brunnermeier and Parker 2005), we require that the agent's action decision be consistent with the chosen belief. Consequently, as the agent chooses a belief that deviates farther from his prior, he chooses an action that deviates farther from the optimal action, leading to a lower expected material payment. To capture this deviation penalty succinctly, we introduce a penalty function $p(\hat{\pi}, \pi) .{ }^{28}$ This function captures the

\footnotetext{
${ }^{23}$ This assumption can be microfounded in multiple ways. As an example, consider a person choosing a level of prayer intensity $a$. Let the effort cost be an increasing, differentiable, and convex function of the action $-c(a)$ - and the material benefit be an increasing, differentiable, and concave function $-b(a)-$ which accrues only in the religious state. This leads to a material payoff of $\pi b(a)-c(a)$, which has a unique maximizer $a^{*}(\pi)$ that is increasing in $\pi$. Assuming that $b(a)$ satisfies the Inada conditions further guarentees that $a^{*}(\pi)$ is strictly increasing in $\pi$.

${ }^{24}$ Following much of the economics literature on belief manipulation, we abstract from the process by which beliefs are chosen. It is often hypothesized that individuals may select sources of information in a way that introduces bias and then omit to correct for that bias when processing their information. Pascal himself considered that the choice of beliefs may follow a less than instantaneous process that relies on self-selecting into religious practices and environments.

${ }^{25}$ The mapping of belief to salvation is central to Pascal's arguments and, according to Durkheim, "The first article in every creed is the belief in salvation by faith." (Durkheim 1915) (p. 416). This mapping is evident in many passages of the Bible (e.g., John 3:16-18: "Whoever believes in him shall not perish but have eternal life...but whoever does not believe stands condemned...).

${ }^{26}$ This discontinuous formulation is not necessary for our main result below on the emergence of faith. We revisit this issue after presenting our results.

${ }^{27}$ The Bible strongly differentiates rewards to full believers relative to all others (e.g., James 1:6: "But he must ask [of God] in faith without any doubting...For that man ought not to expect that he will receive anything from the Lord.")

${ }^{28}$ Pascal's simplest formulation involved a spiritual benefit and no costs from beliefs, yielding a simple
} 
difference in expected material payoff - calculated using the agent's prior - between taking the (material-payoff-maximizing) action associated with the prior and the action associated with the chosen belief. We assume that $p(\hat{\pi}, \pi)$ is continuous, twice-differentiable, minimized at 0 when $\hat{\pi}=\pi$, so the penalty increases as $\hat{\pi}$ deviates farther from $\pi\left(\frac{\partial p(\hat{\pi}, \pi)}{\partial \hat{\pi}} \lesseqgtr 0\right.$ for $\hat{\pi} \lesseqgtr \pi) \cdot{ }^{29}$

Given these assumptions, the agent will choose a belief $\hat{\pi}$ given his prior $\pi$ to maximize: ${ }^{30}$

$$
U(\hat{\pi}, \pi)=\pi U_{r}(\hat{\pi})-p(\hat{\pi}, \pi)
$$

\subsection{Predictions: Extreme Beliefs and Belief Elasticity}

The agent's maximization problem is intuitive: the benefit of faith is the spiritual payoff in the religious state, while the cost is a distorted action in the non-religious state. An agent with a low prior on the religious state perceives the spiritual benefit as unlikely and the cost from a distorted action as likely, rendering faith an unappealing choice. As the prior rises toward 1, the expected cost monotonically falls toward zero, and the expected benefit monotonically rises to $u_{r}$. Therefore, there is some prior $\pi^{\prime}<1$ for which expected costs equal benefits, and all agents with a higher prior will choose full belief (we assume the marginal type, being indifferent, remains skeptical). This is established in our first,

Proposition 1 If $u_{r}>0$, then there exists a type $\pi^{\prime} \in(0,1)$ such that all types $\pi>\pi^{\prime}$ choose to fully believe in the religious state (they set $\hat{\pi}=1$ ) and all types $\pi \leq \pi^{\prime}$ remain skeptics and retain their priors (they set $\hat{\pi}=\pi$ ).

There are three aspects to this result: full believers will emerge, others will instead retain their priors, and there is no partial belief manipulation. While our formulation of spiritual payoffs in (1) matters for the last aspect (so partial faith may be observed with a continuously increasing spiritual payoff $\left.U_{r}(\hat{\pi})\right)$, it is not necessary for the first two. ${ }^{31}$

dominance argument. Anticipating possible objections, he added two expected value arguments which allow mistaken beliefs to carry a penalty (Hacking 1972), just as we model here. In order to justify belief by those who are strongly skeptical, Pascal invoked infinite payoffs from Heaven, implying that any person with a non-zero prior should choose to believe.

${ }^{29}$ Returning to the previous prayer example, $p(\hat{\pi}, \pi)$ can be written as $\left[\pi b\left(a^{*}(\pi)\right)-c\left(a^{*}(\pi)\right)\right]-\left[\pi b\left(a^{*}(\hat{\pi})\right)-\right.$ $\left.c\left(a^{*}(\hat{\pi})\right)\right]$, where $a^{*}(\pi)=\arg \max \pi b\left(a^{*}(\pi)\right)-c\left(a^{*}(\pi)\right)$. Given our previous assumptions, the assumptions in the text about $p(\hat{\pi}, \pi)$ hold.

${ }^{30}$ We drop from the maximization problem the material payoff from the optimal action associated with the agent's prior $-\left[\pi b\left(a^{*}(\pi)\right)-c\left(a^{*}(\pi)\right)\right]$ in the prayer example - as it is a constant.

${ }^{31}$ Consider $U_{r}(\hat{\pi})$ to be continuously increasing and differentiable. The result that an interval of types choose a full belief $\hat{\pi}=1$ just requires that $\frac{d U_{r}(\hat{\pi})}{d \pi}>0$ in a neighborhood of $\hat{\pi}=1$, because $p(\hat{\pi}, \pi)$ has slope zero at $\hat{\pi}=\pi$. That those with low enough priors must engage in no belief manipulation still obtains under 
The second prediction of the model is that chosen beliefs change in response to changes in the penalty function. For example, if there is a larger penalty for deviating from priors - e.g., a religion demands more costly actions from believers - then, the number of people who choose to believe fully will fall. To formalize this logic, define $\widetilde{p}(\hat{\pi}, \pi)$ as universally more costly than $p(\hat{\pi}, \pi)$ if $\widetilde{p}(\hat{\pi}, \pi)>p(\hat{\pi}, \pi)$ when $\hat{\pi} \neq \pi$ (recall that, by definition, $\widetilde{p}(\pi, \pi)=$ $p(\pi, \pi)=0)$. Given this, we show:

Proposition 2 If $u_{r}>0$, a change from $p(\hat{\pi}, \pi)$ to the universally more costly penalty function $\widetilde{p}(\hat{\pi}, \pi)$ leads to a higher indifferent type $\pi^{\prime}$ and consequently a smaller interval of priors leading to full belief.

\subsection{Experiment: Measuring Beliefs and Testing Elasticity}

Our experiment was designed to achieve two objectives: to measure beliefs in a religious state using an incentive compatible mechanism and to test if these beliefs would change given a higher material cost to distorted beliefs.

For measurement, the particular nature of the religious belief in the Rapture - that money will have no value once the Rapture occurs - eliminates the possibility of some desirable belief-elicitation mechanisms. For example, to the best of our knowledge, mechanisms that are robust to risk-aversion (see Karni (2009), inter alia) require agents to value monetary payments in all states of the world following the resolution of uncertainty. As an alternative, we used a BDM-like mechanism in which the agent makes a set of choices between an immediate monetary payment of $\$ 5$ and different (larger) monetary payments to be received after May 21st, with each choice having the potential to be implemented. ${ }^{32}$ Following the standard logic on the BDM mechanism, the agent's optimal decision is simple: choose the immediate payment unless the later payment is so large that its expected utility is higher. Given a utility function $u(\cdot)$, wealth $w$, a discount factor $\delta$, and a belief in the Rapture $\hat{\pi}$, the agent will switch to the later payoff at the cutoff choice:

the mild assumption that $\lim _{\hat{\pi} \rightarrow 0} U_{r}(\hat{\pi})=0$. In addition, the qualitative results on elasticity established later will hold if $p(\widehat{\pi}, \pi)$ is not too convex given the other parameters in the model.

${ }^{32}$ More formally, in our protocol, the agent expresses a cutoff decision $x \in[1,500]$. This cutoff expresses the lowest amount the subject would be willing to accept in four weeks in exchange for an amount $\$ 5$ payable today. A random number $y \in Y$ is drawn, where $Y$ is a finite set of values with typical element $y_{i}$ lying between 1 and 500, and where each value $y_{i}$ is drawn with probability $h\left(y_{i}\right)$, with $H\left(y_{i}\right)$ denoting the associated cumulative probability. If $y \leq x$ then the subject gets paid $\$ 5$ through a present-dated check. If $y>x$, then the subject gets paid $y$ through a check post-dated by four weeks. Then, the subject's expected material payoff from the implementation of the experiment can be written as: $v(x, \pi) \equiv H(x) u(5)+\delta(1-$

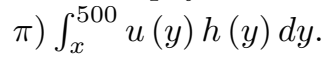




$$
x^{*}(\hat{\pi})=u^{-1}\left(\frac{u(w+5)}{\delta(1-\hat{\pi})}\right)-w .
$$

Our mechanism is not robust to risk-aversion: knowledge of $u(\cdot)$ and $w$ is required to back out beliefs $\hat{\pi}$. In the results section, we use risk-neutrality as a baseline as it leads to a particularly simple formula for beliefs: $\hat{\pi}=1-\frac{5}{\delta x^{*}}$. We then show that the results are very robust to different assumptions about risk aversion. Note that equation 3 links beliefs with experimental choices regardless of the origin of beliefs; i.e., if people retain their priors rather than choosing beliefs as we have modeled, the same equation holds with $\hat{\pi}$ replaced by $\pi$.

To measure elasticity, we experimentally modify the penalty function by varying the probability $q$ that, after the subject chooses a cutoff, the BDM mechanism will actually be implemented. ${ }^{33}$ To understand this experimental manipulation, consider the effect of augmenting the model with the experiment. That is, in period 2 the agent must additionally choose a cutoff $x$ (which must be consistent with his chosen beliefs); then a first draw determines if the mechanism will be implemented at all and, if it is, a second draw determines the implemented choice, leading to a monetary payment now (period 2) or later (period 3), depending on the agent's cutoff decision. Define the expected experimental payoff to the subject choosing a cutoff $x$ given a prior $\pi$ as $q \cdot v(x, \pi)$. The agent maximizes this expected experimental material payoff by choosing the cutoff $x^{*}(\pi)$ defined above. If the agent chooses a different belief $\hat{\pi}$, he is required by consistency to choose cutoff $x^{*}(\hat{\pi})$, which under the prior $\pi$ leads to a lower expected payoff. In other words, the net effect of adding the experiment is a modification of the penalty function from $p(\hat{\pi}, \pi)$ to $\widetilde{p}(\hat{\pi}, \pi):^{34}$

$$
\widetilde{p}(\hat{\pi}, \pi) \equiv p(\hat{\pi}, \pi)+q\left(v\left(x^{*}(\pi), \pi\right)-v\left(x^{*}(\hat{\pi}), \pi\right)\right)
$$

which implies,

Corollary 1 (To Proposition 2)As an increase in the probability of implementation $q$ leads to a universally more costly penalty function, it leads to a higher indifferent type $\pi^{\prime}$ and consequently a smaller interval of priors leading to full belief.

If changes in $q$ led to changes in reported beliefs it would mean that incentives shape

\footnotetext{
${ }^{33}$ For simplicity, we assume that the experimental payoff is separable from the previously discussed, nonexperimental, expected material payoff.

${ }^{34} \mathrm{~A}$ potentially more natural method of modifying the penalty function is to vary prizes across experimental treatments rather than the probability of implementation. However, this method introduces income effects. If utility is concave, it becomes impossible to disentangle effects stemming from changes in income versus changes in beliefs. Our manipulation of $q$ avoids this identification pitfall.
} 
beliefs. Unfortunately, given our setup, the opposite is not true: finding a zero elasticity does not imply that choice is absent from the process of belief formation. Various possibilities could deliver a zero elasticity. One is that there are no marginal subjects around $\pi^{\prime}$ in our sample. If small changes in the prior $\pi^{\prime}$ that separates full believers from skeptics occur but there are no subjects in the neighborhood of $\pi^{\prime}$, no effects will be detected. Second, while the incentives we offered are fairly large in the context of field experiments, they may be low for our particular context. Third, subjects might take a while to reoptimize beliefs, or not be able to reoptimize at all once they hold beliefs that are chosen and also extreme. ${ }^{35}$

\section{Results}

\subsection{Participant Summary Statistics}

Table 1 contains summary statistics for both the FR (columns 1 and 2) and SDA (columns 3 and 4) samples, split by group and condition. Columns 3 and 6 contain p-values of tests of equality across treatment conditions. Column 7 contains p-values of tests of equality across treatment groups. No observable characteristics are significantly different across treatment conditions, within samples. The only variable that is significantly different across treatment groups is expected: the FR subjects state strong (unincentivized) beliefs that the Rapture will occur on May 21st while the SDA subjects do not. Note that some questions in Table 1 were asked after the experimental intervention and therefore could have been influenced by the treatment; however, given the benign nature of the experimental variation, along with the theological centrality of the post-experiment survey questions, we believe this type of bias is unlikely to have occurred.

The first two rows of Table 1 show that subjects from both samples are on average middle aged and slightly more than half are male. Perhaps not surprisingly, the vast majority of Family Radio members stated that they believed Harold Camping's prophecy with certainty and had spent significant time "spreading the word." Very few SDA members believed that May 21st was the day of Judgement, despite the fact that $80 \%$ had heard about Harold Camping's prophecy. Panel A of figure 1 contains the empirical distribution of these beliefs for both samples as captured through a survey instrument. The beliefs of FR subjects are extreme in that very few hold interior beliefs, in line with the theoretical predictions of our

\footnotetext{
${ }^{35}$ It may be argued that since FR subjects were likely full believers that could therefore not reoptimize, the possibility of finding empirically a non-zero elasticity is precluded. A previous version of this paper demonstrates formally that if subjects reoptimize by at least partly resorting to an original prior held before their choice of faith, then a positive elasticity could be observed.
} 
model. ${ }^{36}$

Subjects from both groups expressed uncertainty about whether they would be raptured on Judgement Day. This likely stems from scripture such as Revelation 14:3-4, which states that only a small number of people (specifically, 144,000) will be raptured, and Romans 3:10, which states that "no one is righteous." Some subjects may have felt that expressing certainty in one's Rapture prospects was a violation of biblical authority, whereas others felt comfortable doing so.

Overall, the summary statistics confirm that SDA members are similar in many respects to FR members, but rather than having a date-specific Judgement Day belief, most believe it will come at some unspecified time in the future (which is consistent with Church doctrine). SDA members put positive probability on Judgement Day happening within their lifetime, with an average of about $40 \%$ probability. This is further evidence that large, closer to mainstream, religious groups such as the SDA hold what many would consider "extreme" beliefs. For example, the question "What is life going to be like on Earth after Judgement Day?" yielded similar responses from both samples, centering on destruction, chaos, and suffering.

\subsection{Experimental Findings}

Panel B of figure 1, contains the main results of the incentivized experiment. The histogram contains cutoff values - that is, the minimum amount of money a subject was willing to accept in four weeks in exchange for $\$ 5$ today - for each of the FR and SDA samples, separating the $6 \%$ and $50 \%$ conditions. Visually it is clear that the FR and SDA groups lie on opposite extremes. The distributions of cutoffs are statistically different across the two groups regardless of whether one separates the two conditions or pools them. Panel A of Table 2 reports results by pooling the $6 \%$ and $50 \%$ conditions. The p-value for a Wilcoxon Rank Sum test of different distributions of cutoffs across the groups is below 0.01. Across groups, the correlation between the cutoffs and the unincentivized probabilistic assessment (shown in Panel A) is $\rho=0.946$, which is highly statistically significant $(p-$ value $<0.001)$.

Table 2 also shows that the average cutoff for SDA subjects was about $\$ 20$ and the median was $\$ 8$. Taking this median, SDA members chose to delay payment for a "reasonable" time-discount, one month out, of $5 / 8=0.625$, which lies within the range of values found by laboratory studies (Frederick, Loewenstein, and O'Donoghue 2002) (using the mean also yields a comparable discount). This suggests that the bulk of SDA survey responses indicat-

\footnotetext{
${ }^{36}$ SDA members could also be seen to hold extreme beliefs, which in light of our model could reflect low original priors or a low threshold $\pi^{\prime}$ separating skeptics and believers.
} 
ing no belief in the prophecy were sincere, and we can take their median discount factor as our estimate for $\delta$. In contrast, FR members chose very large cutoffs: only one subject chose a cutoff less than $\$ 500$ (specifically, a $\$ 200$ cutoff, by a subject who in the survey declared less than full beliefs in the prophecy). All other FR subjects declared to prefer $\$ 5$ today to any amount up to $\$ 500$ payable one month out. This is compatible with cutoffs much higher than $\$ 500$, and potentially infinite. To be conservative, we impute a cutoff of $\$ 500$ for these subjects. This yields a median cutoff among FR subjects of $\$ 500$, and an average of $\$ 487$.

What do the cutoffs chosen by FR members imply in terms of the strength of their beliefs in the Rapture? Using the formula in (3) we now compute the implied beliefs under the assumption of risk neutrality, using the SDA discount factor to approximate $\delta$. Taking the median cutoff for the FR members (equal to \$500), the implied belief in the Rapture is $\hat{\pi}=1-\frac{5}{0.625 \times 500}=98.6 \%$. If we take the average cutoff for the FR members (equal to \$487), the implied belief in the Rapture is virtually identical: $98.56 \%$. Note that these are conservative estimates: if the cutoffs we impute as $\$ 500$ were replaced with larger figures the estimated value of $\hat{\pi}$ would get even closer to $100 \% .{ }^{37}$ This is consistent with the unincentivized question in the survey, where FR members expressed certainty about the Rapture. The fact that the cutoffs chosen by SDA members are compatible with previous estimates of time preference provides reassurance that the cutoffs chosen by the FR members were likely not an artifact, but instead reflect strong and sincere beliefs in the May 21st prophecy. $^{38}$

As made clear in Panel B of figure 1, there is no visible difference across conditions within the FR and the SDA groups. This is borne out in the statistical tests reported in Panel B of Table 2. This table displays cutoff means and medians across conditions for each group, as well as their differences and the associated non-parametric p-values. There are no significant differences across conditions for either group.

\footnotetext{
${ }^{37}$ It is easy to show that if SDA members have non-zero beliefs in the Rapture, the computed belief for FR members will only rise and therefore our estimate can again be seen as a lower bound. Lastly, the reader may wonder about our use of a discrete elicitation mechanism. Given the median of $\$ 8$ (or, alternatively, the average of $\$ 20$ ) for the SDA cutoffs, it is conceivable that the true cutoffs lie in between 8 and 9 for the median or 20 and 22 for the average. Taking any value in the interval between the declared notch and the next discrete value available in the scale yields an even higher estimate of $\hat{\pi}$ for the FR subjects.

${ }^{38}$ Even extreme risk aversion does not change our qualitative results. By way of illustration, consider a person with greater than $\$ 100$ of wealth and a certainty equivalent $\$ 100$ for a fifty-fifty gamble over zero and $\$ 500$ (that is, quite extreme risk aversion). Given a CRRA utility function $\left(u(c)=\frac{c^{1-\rho}}{1-\rho}\right)$ or a CARA utility function $\left(u(c)=1-e^{-\alpha c}\right)$, our calculation in the text would change from a lower bound of $98.6 \%$ to lower bounds of $97.1 \%$ and $94.6 \%$, respectively.
} 


\subsection{Discussion of Results}

Our first finding is evidence of a sincere and full belief in the Rapture by $\mathrm{FR}$ members given varying, and nontrivial, financial stakes. The responses of SDA members, a theologically similar group, suggest that these findings were not driven by confusion or distrust in the experimental methods. We find a close correspondence between the responses of a non-incentivized survey instrument and the financially-incentivized experiment, providing evidence that our results were not driven by demand effects. ${ }^{39}$ The sharp separation of beliefs between skeptics and full beliefs is compatible with the Pascalian wager logic of our model.

However, we do not find evidence for a price elasticity of beliefs, the second main prediction of the model. The lack of evidence, unfortunately, does not allow us to adjudicate between our model and alternative theories. On the one hand, the results do not disprove our theory. The theory predicts that a group of marginal individuals will change beliefs given a higher penalty for choosing a full belief, but there are many reasons why these individuals might not occur in our sample. Our experimental payoffs might have been to too low to capture marginal individuals, and beliefs might take a longer time to adjust than the experiment allowed. ${ }^{40}$ Also, our sample might have been biased towards non-marginal individuals; note that our FR participants, as revealed by the experiment, had previously selected a full belief. If belief reoptimization is based on that chosen, extreme, belief (as opposed to at least partly recovering a pre-faith prior) subjects would perceive no tradeoffs and have inelastic beliefs.

On the other hand, there are alternative theories that might explain our empirical findings, such as Bayesian updating with degenerate initial priors or the differential observation of strong opposing signals by the different subject groups. We are reluctant to endorse these alternatives for a few reasons. We find the Bayesian interpretation of such extreme and sincere beliefs problematic: in addition to the apparent lack of strong evidence to support certainty in the prophecy, Bayesians with interior priors should converge rather than diverge over time. While it might be that subjects simply "started off" with priors that match our observed elicited beliefs, this interpretation suggests a world in which people get "given" extreme beliefs and never learn or contemplate alternatives before accepting those beliefs.

\footnotetext{
${ }^{39}$ Demand effects and expressive motives should be expected to be more acute in the survey instrument. Research in political science shows that incentivized elicitation of opinions on political facts sharply reduces the partisan bias seen in surveys (Bullock and Huber 2013).

${ }^{40}$ It is natural to wonder if true believers would have been able to pass up $\$ 5000, \$ 500,000$, or $\$ 5,000,000$ in order to actively entertain the idea that the Judgement Day would not happen on May 21st. Unfortunately, IRB restrictions against large sums that could be considered coercive (as well as our research budget) prevented us from using larger experimental prizes.
} 
Therefore, our preferred interpretation is one that postulates some process of belief formation, which suits history given the novelty of the prophecy, and as encoded in our model: individuals use some discretion when setting beliefs and do so differently, reflecting differential wills to believe motivated by originally dispersed priors. Nonetheless, the fact is that our experimental results do not provide a "smoking gun" for our conceptualization and therefore we look to future research to identify the precise way in which incentives may shape religious beliefs.

\subsection{Epilogue: Adjusting to the Prophecy Failure}

The vast majority of FR members reported in our survey that they were a $100 \%$ certain that the Rapture would occur on May 21st, 2011. Their choices the incentivized time-preference experiment were consistent with this belief. However, the Rapture did not occur on May 21st. How did the FR members react?

After May 21st it became extremely difficult to contact FR members directly. ${ }^{41}$ Fortunately, in addition to the large number of news reports following the event, many members continued to participate in a online forum dedicated to the discussion of the May 21st prophecy. The message board was hosted on Yahoo! and was open to the public to read, but required joining the group with moderator approval in order to post messages. ${ }^{42}$ We downloaded all 1538 message board posts one month before and one month after May 21, 2011, and instructed a research assistant to encode the message content in a quantitative format (such as noting quoted Bible verses, mentioned dates, subjective ranking of emotional tone, etc.).

The initial prediction about the timing of the Rapture was very specific. According to Harold Camping, the Rapture would begin in the first time zone to experience sunset on May 21st (UTC+12, which contains New Zealand) and travel around the world as the sun set on different time zones. In the preceding days, the message board largely included messages about faith, hope, and goodbyes to other members. The board was relatively quiet in the few hours preceding and following the predicted starting time. A few hours after this time, some members began to speculate about what was (or was not) happening. The messages revealed an anxiety for a resolution that would maintain the central tenets of the prophecy.

A manifestation of that sentiment involved posts putting forth alternative future dates for the Rapture. The new dates tended to involve minimal amendments to the original theory,

\footnotetext{
${ }^{41}$ Our protocol as approved by IRB required and assured anonymity, and therefore we could not recontact FR members. To our knowledge, the group did not meet publicly after May 21.

${ }^{42}$ The forum, with all posted messages, is located at http://groups.yahoo.com/group/ TimeandJudgment_May212011/.
} 
typically predicting the Rapture to occur within one day of the posting. For example, two hours after the originally predicted Rapture time, the moderator of the board posted a 6,600 word essay about a potential error in Camping's interpretation of time, suggesting that the Rapture would occur at Midnight in Jerusalem time. This theory was endorsed by eight other posts in the next few hours. Immediately after that time passed, someone noted that the previous theory had not taken Daylight Savings Time into account, potentially extending the margin by another hour. Following the passing of each new predicted time, a new revision was immediately suggested and the group coalesced on that time. This active revision of the prediction with dates very close to May 21st continued until about the time Camping reappeared on radio on May 23rd. He stated that the "spiritual judgement" entailed by the Rapture had occurred indeed, albeit without any visible signs. He also stated that creation would still be destroyed on October 21st, 2011.

It is interesting to note the re-setting of dates after a failed prophecy is quite typical of apocalyptic groups (Kyle 1998). For example, following the Millerites' failed prophecy of 1843, a large faction of the group quickly converged on March 21, 1844 as a new date for the End of the World, and when that date passed uneventfully, new dates in 1874, then 1878, then 1881 were adopted by the leaders that would go on to form the Jehovah's Witnesses. ${ }^{43}$

The FR members' pattern of behavior (amending the prophecy time) can be related to the notion of a demand for beliefs, linked to a supply of predictions and narratives. Given the failure of the original prediction, the "consumers" in this market for apocalyptic predictions attempted their own production. This process lasted until the "official" supplier of such predictions - Camping, in the FR case - produced a new one. This behavior provides another suggestion that individuals have a demand for beliefs, one that can only be exercised if there is something - in this case a prediction - to believe in.

\section{Conclusion}

A better understanding of faith, that is, of strong beliefs that are by definition not driven by evidence in the logical or statistical sense, is an important task for the economics of religion, and one that may yield insights into decision-making more broadly. In this paper, we study faith through the prism afforded by a recent apocalyptic prophecy. This prophecy allowed us to conduct what to our knowledge is the first ever elicitation of religious beliefs based on

\footnotetext{
${ }^{43}$ The other main faction went on to become the Seventh Day Adventist Church. As has been seen, this group maintained the belief that Judgement Day is near, but abandoned date-setting. In their book on failed prophecies Festinger, Riecken, and Schachter (2009) illustrate how the disconfirmation of beliefs triggers a variety of responses involving adjustments in beliefs and narratives.
} 
a revealed preference, incentivized mechanism.

Our experiment is framed by a theoretical model that incorporates the logic of the Pascalian wager, but can be extended to incorporate a richer set of psychological motives, such as anticipation of future divine rewards. The key driver in the model is the rational manipulation of beliefs once these enter as arguments in a state-contingent utility function. Our model predicts manipulation of beliefs towards complete faith for a certain interval of priors. It also explains how the experimental intervention can establish the presence of sincere religious beliefs and yield estimates of their response to changes in the cost of holding them.

Our evidence indicates the existence of a sincere belief in the end of the world by members of the apocalyptic group. The main import of this finding is to highlight the role of sincere faith in a particular religious belief system, beyond other, mundane, motivations that could affect the demand for religion. In addition, our data suggests that the beliefs are inelastic to changes in costs, although this result may be dependent on a small sample size, or pertinent to the short run only.

Partly through its limitations, our study suggests some avenues for future research. Future projects could consider contacting subjects separately rather than at the end of a collective activity, as well as involve larger samples and larger prizes. The idea of using incentivized elicitation schemes in combination with falsifiable religious statements could be extended to other settings; for instance, one could use our approach to study beliefs in the power of prayer to alter observable outcomes. Lastly, in light of our results, it would be important to enrich the market analysis of religion; the demand side could include sincere faith as an active and distinct component that may interact with other motivations to demand religious philosophies or services.

\section{References}

Akerlof, G. A. and W. T. Dickens (1982). The economic consequences of cognitive dissonance. The American Economic Review 72(3), 307-319.

Babcock, L. and G. Loewenstein (1997). Explaining Bargaining Impasse: The Role of Self-Serving Biases. The Journal of Economic Perspectives, 109-126.

Babcock, L., G. Loewenstein, S. Issacharoff, and C. Camerer (1995). Biased Judgments of Fairness in Bargaining. The American Economic Review, 1337-1343.

Barro, R., J. Hwang, and R. McCleary (2010). Religious conversion in 40 countries. Journal for the Scientific Study of Religion 49(1), 15-36. 
Barro, R. and R. McCleary (2006). Religion and political economy in an international panel. Journal for the Scientific Study of Religion 45(2), 149-3175.

Becker, G., M. DeGroot, and J. Marschak (1964). Measuring utility by a single-response sequential method. Behavioral Science 9, 226-232.

Bénabou, R. and J. Tirole (2004). Willpower and personal rules. Journal of Political Economy 112(4), 848-886.

Bénabou, R. and J. Tirole (2006). Incentives and prosocial behavior. American Economic Review 96(5), 1652-1678.

Benoit, J. and J. Dubra (2011). Apparent overconfidence. Econometrica, forthcoming.

Brunnermeier, M. K. and J. A. Parker (2005). Optimal Expectations. The American Economic Review 95(4), 1092-1118.

Bullock, J., G. A. H. S. and G. Huber (2013). Partisan bias in factual beliefs about politics. NBER Working Paper No. 19080.

Camping, H. (2005). Time has an End: A History of the World 11,013 B.C. to 2011 A.D. Vantage Press.

Carrillo, J. D. and T. Mariotti (2000). Strategic ignorance as a self-disciplining device. Review of Economic Studies 67(3), 529-44.

Cohen, D. (1983). Waiting for the Apocalypse. Prometheus Books.

Cohn, N. (1957). The Pursuit of the Millennium. Secker \& Warburg, London.

Compte, O. and A. Postlewaite (2004). Confidence-enhanced performance. American Economic Review 94 (5), 1536-1557.

Dal Bó, E. and M. Tervio (2013). Self-esteem, moral capital, and wrongdoing. Journal of the European Economic Association 11(3), 599-663.

Durkheim, E. (1915). The Elementary Forms of Religious Life. Free Press.

Durkin, J. and A. Greeley (1991). A model of religious choice under uncertainty: On responding rationally to the nonrational. Rationality and Society 3(2), 178-196.

Eil, D. and J. M. Rao (2011). The Good-News Bad-News Effect: Asymmetric Processing of Objective Information about Yourself. American Economic Journal: Microeconomics, $529-544$.

Eliade, M. (1954). The Myth of the Eternal Return. New York: Pantheon Books.

Ensminger, J. (1997). Transaction costs and islam: Explaining conversion in africa. Journal of Institutional and Theoretical Economics (JITE) 153(1), 4-29. 
Festinger, L., H. Riecken, and S. Schachter (2009). When Prophecy Fails. Pinter \& Martin Limited.

Frederick, S., G. Loewenstein, and T. O’Donoghue (2002). Time discounting and time preference: A critical review. Journal of economic literature 40(2), 351-401.

Hacking, I. (1972). The logic of pascal's wager. American Philosophical Quarterly 9(2), 186-192.

Hajek, A. (2003). Waging war on pascal's wager. Philosophical Review 112(1), 27-56.

Hoffman, R. (2012). The Experimental Economics of Religion. Journal of Economic Surveys, $41-71$.

Huber, J. (2005). Religious Belief, Religious Participation, and Social Policy Attitudes Across Countries. Working Paper.

Iannaccone, L. R. (1998). Introduction to the Economics of Religion. Journal of Economic Literature 36(3), 1465-1495.

James, W. (1909). The Will to Believe and Other Essays in Popular Philosophy. E-Book 26659 The Project Gutenberg ihttp://www.gutenberg.org/files/26659/26659-h/26659h.htmP1i.

Karni, E. (2009). A mechanism for eliciting probabilities. Econometrica 77(2), 603-606.

Köszegi, B. (2006). Ego utility, overconfidence, and task choice. Journal of the European Economic Association 4(4), 673-707.

Krosnick, J. A. and S. Presser (2009). The theory of the firm. In J. D. Wright and P. V. Marsden (Eds.), Handbook of Survey Research. Elsevier.

Kuran, T. (1995). Private Truths, Public Lies: The Social Consequences of Preference Falsification. Harvard University Press.

Kyle, R. (1998). The Last Days are Here Again: A History of the End Times. Baker Books (Grand Rapids, Mich.).

Levy, G. and R. Razin (2011). Religious Beliefs, Religious Participation and Cooperation. Working Paper.

Massey, C., J. P. Simmons, and D. A. Armor (2011). Hope over experience: Desirability and the persistence of optimism. Psychological Science 22, 274-281.

McGinn, B. (1998). Visions of the End: Apocalyptic Traditions in the Middle Ages, Volume 96. New York: Columbia Univ Press. 
Michalopoulos, S., A. Naghavi, and G. Prarolo (2012). Trade and geography in the origins and spread of islam. NBER Working Papers 18438.

Möbius, M., M. Niederle, P. Niehaus, and T. Rosenblatt (2010). Self-confidence Management: Theory and Empirical Evidence. Working paper.

Montgomery, J. D. (1996). Contemplations on the Economic Approach to Religious Behavior. The American Economic Review: Papers and Proceedings 86(2), 443-447.

Palacios-Huerta, I. and T. J. Santos (2004). A theory of markets, institutions, and endogenous preferences. Journal of Public Economics 88(3-4), 601-627.

Pascal, B. (1668). Pascal's Pensees (English translation by John Walker). Available online at http://www.gutenberg.org/files/18269/18269-h/18269-h.htm.

Rowley, H. H. (1943). The Relevance of Apocalyptic: A Study of Jewish and Christian Apocalypses From Daniel to the Revelation. London: Lutterworth Press.

Santos-Pinto, L. and J. Sobel (2005). A model of positive self-image in subjective assessments. American Economic Review, 1386-1402.

Soibelman, M. (2004). Palestinian suicide bombers. Journal of investigative psychology and offender profiling 1 (3), 175-190.

Svenson, O. (1981). Are we all less risky and more skillful than our fellow drivers? Acta Psychologica $47(2), 143-148$.

Wagar, W. W. (1982). Terminal Visions: the Literature of Last Things. Bloomington, Indiana: Indiana University Press.

\section{Appendix}

Proof of Proposition 1: For an agent with prior $\pi$, the payoff from choosing $\hat{\pi}=1$ is $U(1, \pi)=\pi u_{r}-p(1, \pi)$ and the payoff from choosing $\hat{\pi}<1$ is $U(\hat{\pi}, \pi)=-p(\hat{\pi}, \pi)$. Note that, given the properties of $-p(\hat{\pi}, \pi)$, an agent that chooses $\hat{\pi}<1$ attains a maximum payoff of 0 by setting $\hat{\pi}=\pi$ and therefore any agent choosing $\hat{\pi}<1$ must choose $\hat{\pi}(\pi)=\pi$. Consequently, $\hat{\pi}(0)=0$. By continuity of $p(\hat{\pi}, \pi)$, for any finite value $u_{r}$ there exists an interval of types above $\pi=0$ who also choose $\hat{\pi}(\pi)=\pi$. Now note that $\hat{\pi}(1)=1$ as both components of $\pi U_{r}(\hat{\pi})-p(\hat{\pi}, \pi)$ are separately maximized at $\hat{\pi}=1$. Finally, note that $U(1, \pi)$ is continuous and increasing in $\pi$ given the properties of $p(\hat{\pi}, \pi)$ and therefore there exists some type $\pi^{\prime} \in(0,1)$ such that $U\left(1, \pi^{\prime}\right)=0=U\left(\pi^{\prime}, \pi^{\prime}\right)$. Therefore, for all types $\pi>\pi^{\prime}$, $U(1, \pi)>0$ and $\hat{\pi}(\pi)=1$ while for all types $\pi<\pi^{\prime}, U(1, \pi)<0$ and $\hat{\pi}(\pi)=\pi$. 
Proof of Proposition 2: By Proposition 1, there exists one type $\pi^{\prime} \in(0,1)$ given $p(\hat{\pi}, \pi)$ such that $U\left(\pi^{\prime}, \pi^{\prime} ; p(\hat{\pi}, \pi)\right)=U\left(1, \pi^{\prime} ; p(\hat{\pi}, \pi)\right)$ and $U(\pi, \pi ; p(\hat{\pi}, \pi))>U(1, \pi ; p(\hat{\pi}, \pi))$ for all $\pi<\pi^{\prime}$ and $U(\pi, \pi ; p(\hat{\pi}, \pi))<U(1, \pi ; p(\hat{\pi}, \pi))$ for all $\pi>\pi^{\prime}$. Similarly, there exists another indifferent type $\widetilde{\pi}^{\prime} \in(0,1)$ given $\widetilde{p}(\hat{\pi}, \pi)$. Rewriting the equality relationship for $\pi^{\prime}$ using the definition of $U(\hat{\pi}, \pi)$ yields: $U_{r}\left(\pi^{\prime}\right)-p\left(\pi^{\prime}, \pi^{\prime}\right)=\pi^{\prime} U_{r}(1)-p\left(1, \pi^{\prime}\right)$. Given that $U_{r}\left(\pi^{\prime}\right)=0, U_{r}(1)=u_{r}$, and the fact that $p\left(\pi^{\prime}, \pi^{\prime}\right)=0$ implies that this can be rewritten as $0=\pi^{\prime} u_{r}-p\left(1, \pi^{\prime}\right)$. As $\widetilde{p}(\hat{\pi}, \pi)$ is universally more costly, $p\left(1, \pi^{\prime}\right)<\widetilde{p}\left(1, \pi^{\prime}\right)$, so $0>\pi^{\prime} u_{r}-\widetilde{p}\left(1, \pi^{\prime}\right)$. But, then $\left.U\left(\pi^{\prime}, \pi^{\prime} ; \widetilde{p}(\hat{\pi}, \pi)\right)=0<\pi^{\prime} u_{r}-\widetilde{p}\left(1, \pi^{\prime}\right)=U\left(1, \pi^{\prime} ; \widetilde{p}(\hat{\pi}, \pi)\right)\right)$. But, then, by the definition of $\widetilde{\pi}^{\prime}, \pi^{\prime}<\widetilde{\pi}^{\prime}$.

Proof of Corollary 1: $v\left(x^{*}(\pi), \pi\right)-v\left(x^{*}(\hat{\pi}), \pi\right)>0$ by definition of $x^{*}(\pi)$. Therefore, for a given $\pi$ and $\hat{\pi}, \widetilde{p}(\hat{\pi}, \pi) \equiv p(\hat{\pi}, \pi)+q\left(v\left(x^{*}(\pi), \pi\right)-v\left(x^{*}(\hat{\pi}), \pi\right)\right)$ is rising with $q$, implying that penalty function is universally more costly as $q$ rises and therefore Lemma $\mathbf{2}$ holds. 
Table 1: Summary statistics for FR and SDA groups, by treatment.

\begin{tabular}{|c|c|c|c|c|c|c|c|}
\hline & \multicolumn{3}{|c|}{ Family Radio } & \multicolumn{3}{|c|}{ 7th Day Adventists } & \multirow{2}{*}{$\begin{array}{c}\text { All } \\
\text { p-value } \\
(1,2)=(3,4)\end{array}$} \\
\hline & $6 \%$ & $50 \%$ & $\begin{array}{l}\text {-value } \\
(1)=(2)\end{array}$ & $6 \%$ & $50 \%$ & $\begin{array}{l}\mathrm{p} \text {-value } \\
(4)=(5)\end{array}$ & \\
\hline & (1) & (2) & (3) & (4) & (5) & (6) & (7) \\
\hline Age & $\begin{array}{l}42.1 \\
(5.9)\end{array}$ & $\begin{array}{l}40.7 \\
(5.2)\end{array}$ & 0.86 & $\begin{array}{l}33.5 \\
(4.7)\end{array}$ & $\begin{array}{l}38.6 \\
(4.6)\end{array}$ & 0.44 & 0.32 \\
\hline Percent male & $\begin{array}{c}0.73 \\
(0.14)\end{array}$ & $\begin{array}{c}0.44 \\
(0.17)\end{array}$ & 0.21 & $\begin{array}{c}0.55 \\
(0.16)\end{array}$ & $\begin{array}{c}0.50 \\
(0.13)\end{array}$ & 0.82 & 0.59 \\
\hline $\begin{array}{l}\text { Belief rapture will } \\
\text { occur on May } 21\end{array}$ & $\begin{array}{l}95.0 \\
(4.5)\end{array}$ & $\begin{array}{l}90.6 \\
(8.7)\end{array}$ & 0.65 & $\begin{array}{c}8.3 \\
(5.6)\end{array}$ & $\begin{array}{c}6.1 \\
(4.2)\end{array}$ & 0.75 & 0.00 \\
\hline $\begin{array}{l}\text { Percent that knew about } \\
\text { May } 21 \text { theory }\end{array}$ & - & - & - & $\begin{array}{c}0.75 \\
(0.13)\end{array}$ & $\begin{array}{c}0.87 \\
(0.09)\end{array}$ & 0.47 & - \\
\hline $\begin{array}{l}\text { Belief rapture will } \\
\text { occur in own lifetime }\end{array}$ & - & - & - & $\begin{array}{c}30.0 \\
(10.0)\end{array}$ & $\begin{array}{c}45.7 \\
(10.8)\end{array}$ & 0.30 & - \\
\hline $\begin{array}{l}\text { Hours/week proselytizing } \\
\text { about May } 21^{*}\end{array}$ & $\begin{array}{c}3.7 \\
(0.5)\end{array}$ & $\begin{array}{c}2.9 \\
(0.8)\end{array}$ & 0.41 & - & - & - & - \\
\hline $\begin{array}{l}\text { Belief personally saved } \\
\text { on Judgement Day** }\end{array}$ & $\begin{array}{l}86.1 \\
(7.1)\end{array}$ & $\begin{array}{l}77.9 \\
(14.5)\end{array}$ & 0.61 & $\begin{array}{l}60.0 \\
(11.6)\end{array}$ & $\begin{array}{c}73.3 \\
(11.1)\end{array}$ & 0.41 & 0.19 \\
\hline $\begin{array}{l}\text { Belief End of World will } \\
\text { occur on Oct } 21 \text { given no } \\
\text { sign of May } 21 \text { rapture*** }\end{array}$ & $\begin{array}{l}84.4 \\
(9.7)\end{array}$ & $\begin{array}{c}79.4 \\
(13.2)\end{array}$ & 0.77 & - & - & - & - \\
\hline Observations & 12 & 11 & & 13 & 16 & & \\
\hline
\end{tabular}

Notes: This table holds selection of survey answers across treatment groups and conditions. Robust standard errors in parentheses. ${ }^{*}$ The question about hours/week was asked categorically in the questionnaire, with a maximum choice of six hours per week. ${ }^{* *}$ For the FR group, the question was "With what percent do you believe you will be raptured (saved) on May 21st, 2011?" while for the SDA group, "If the rapture happens in your lifetime, with what percentage do you believe you will be be raptured (saved) on Judgement Day?" ${ }^{* * *}$ Five subjects would not entertain any chance of no rapture on May 21 . These subjects are coded as $100 \%$ belief. 
Figure 1: Histograms of stated beliefs and cutoff values for SDA and FR groups
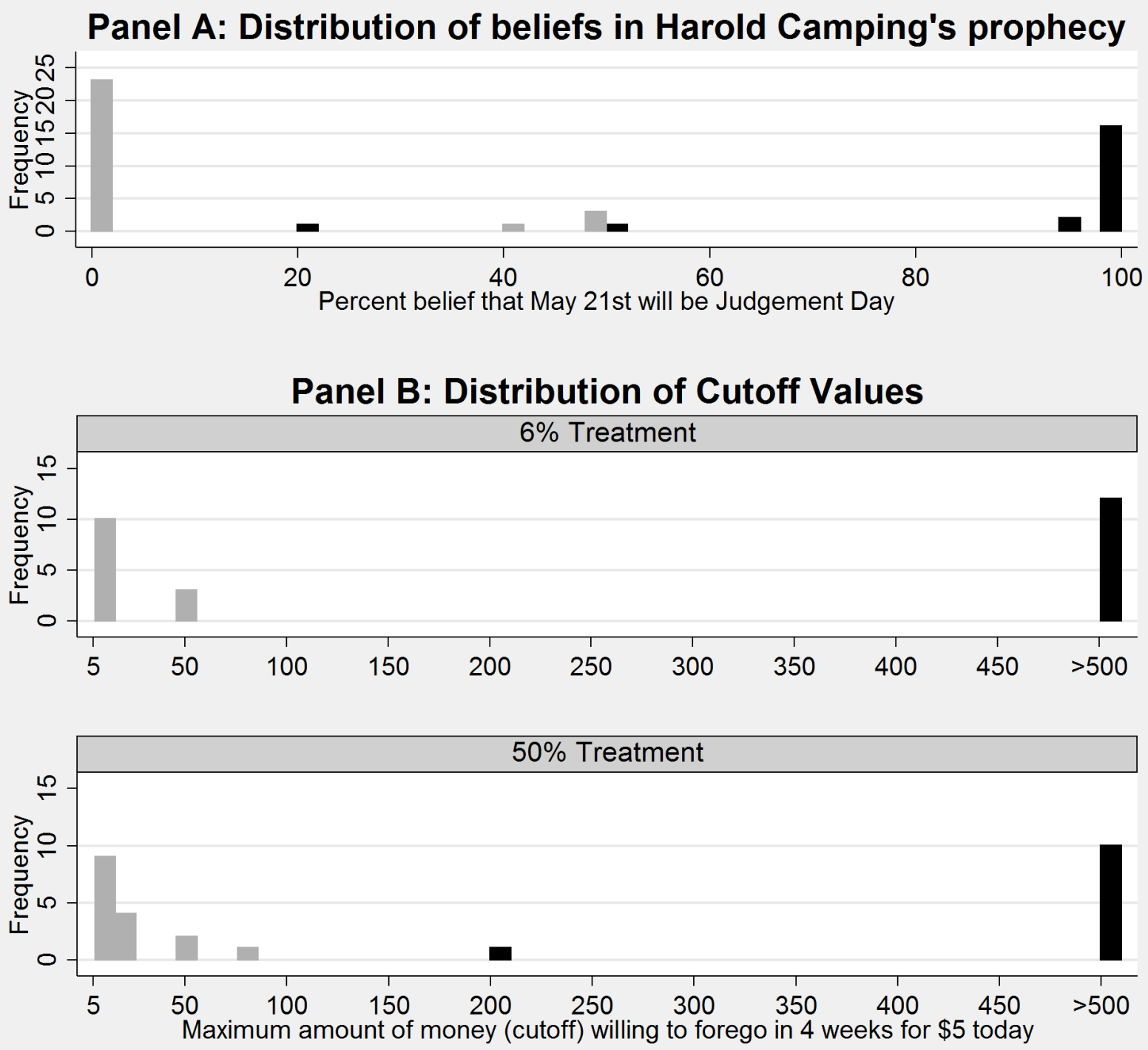

Family Radio

Seventh Day Adventists

Notes:Panel A contains a histrogram of the stated beliefs in the prophecy from the survey instrument by treatment group. Panel B contains the distribution of cutoff values in the experiment, across treatment conditions and by treatment groups. oss FR and SDA groups, while Panel B breaks the results across treatment conditions. We code a subjects' cutoff as $\$ 500$ if they always choose "I prefer $\$ 5$ today" (see text). No subject choose an exact cutoff of $\$ 500$ 
Table 2: Cutoff values for FR and SDA groups, combined and by treatment.

\begin{tabular}{lccc}
\hline \hline & \multicolumn{2}{c}{ Panel A: Pooled conditions } \\
\hline & Family Radio & 7th Day Adventists & $\begin{array}{c}\text { p-value } \\
(1=2)\end{array}$ \\
\cline { 2 - 4 } & $(1)$ & $(2)$ & $(3)$ \\
\hline Cutoff Value & & & \\
Mean & 487.0 & 19.1 & 0.00 \\
\multirow{2}{*}{ Median } & $(13.0)$ & $(3.7)$ & 0.00 \\
& 500 & 8 & \\
Observations & $(0)$ & $(2.8)$ & \\
\hline
\end{tabular}

\begin{tabular}{|c|c|c|c|c|c|c|}
\hline \multicolumn{7}{|c|}{ Panel B: Non-pooled conditions } \\
\hline & \multicolumn{3}{|c|}{ Family Radio } & \multicolumn{3}{|c|}{ 7th Day Adventists } \\
\hline & $\begin{array}{c}6 \% \\
\text { Treatment }\end{array}$ & $\begin{array}{c}50 \% \\
\text { Treatment }\end{array}$ & $\begin{array}{c}\mathrm{p} \text {-value } \\
(1=2)\end{array}$ & $\begin{array}{c}6 \% \\
\text { Treatment }\end{array}$ & $\begin{array}{c}50 \% \\
\text { Treatment }\end{array}$ & $\begin{array}{c}\text { p-value } \\
(4=5)\end{array}$ \\
\hline & $(1)$ & $(2)$ & $(3)$ & (4) & $(5)$ & (6) \\
\hline Cutoff Value & & & & & & \\
\hline Mean & $\begin{array}{l}500.0 \\
(0.0)\end{array}$ & $\begin{array}{l}472.73 \\
(27.1)\end{array}$ & 0.32 & $\begin{array}{l}16.8 \\
(5.3)\end{array}$ & $\begin{array}{l}20.1 \\
(5.2)\end{array}$ & 0.58 \\
\hline Median & $\begin{array}{c}500.0 \\
(0.0)\end{array}$ & $\begin{array}{c}500.0 \\
(0.0)\end{array}$ & 1.00 & $\begin{array}{c}7 \\
(5.3)\end{array}$ & $\begin{array}{c}12 \\
(4.7)\end{array}$ & 0.18 \\
\hline Observations & 12 & 11 & & 13 & 16 & \\
\hline
\end{tabular}

Notes: This table analyzes the cutoff values in the experiment. Panel A analyzes the data across FR and SDA groups, while Panel B breaks the results across treatment conditions. Robust standard errors in parentheses. Median standard errors and p-values are bootstrapped. We code a subjects' cutoff as $\$ 500$ if they always choose "I prefer $\$ 5$ today" (see text). No subject choose an exact cutoff of $\$ 500$. 